\title{
Comportamento de adubos verdes de inverno na região serrana fluminense ${ }^{(1)}$
}

\author{
Carlos Antonio Almeida Barradas ${ }^{(2)}$, Luiz Rodrigues Freire ${ }^{(3)}$, Dejair Lopes de Almeida ${ }^{(4)}$ e Helvécio De-Polli( ${ }^{(4)}$
}

Resumo - O objetivo deste trabalho foi o de avaliar o comportamento de espécies de adubos verdes de inverno, em um Cambissolo Háplico Tb distrófico, sob duas condições de fertilidade, a $1.100 \mathrm{~m}$ de altitude. Dois experimentos de campo foram conduzidos em Nova Friburgo, RJ, utilizando as seguintes espécies: aveia-preta (Avena strigosa Schieb.), azevém-anual (Lollium multiflorum Lam.), chícharo (Lathyrus sativus L.), ervilhaca-comum (Vicia sativa L.), ervilhaca-peluda (Vicia villosa Roth), utilizada somente no segundo experimento, serradela-flor-rosa (Ornithopus sativus Brot.), tremoço-amarelo (Lupinus luteus L.), tremoço-branco cultivar Comum (Lupinus albus L.), tremoço-branco cultivar Multo Lupa Doce (Lupinus albus L.), tremoço-branco cultivar TRM 881 (Lupinus albus L.), trevobranco (Trifolium repens L.), trevo-vermelho cultivar Achylesmarium (Trifolium pratense L.), e trevovesiculoso cultivar Jacuí 52 (Trifolium vesiculosum Savi). O delineamento experimental foi em blocos ao acaso, com três repetições. As espécies que mais se destacaram na produção de massa seca e acumulação de N na parte aérea, sob condições de boa fertilidade no solo, foram as três cultivares de tremoçobranco, o tremoço-amarelo, a ervilhaca-comum e a aveia-preta. Sob condições de baixo teor de P, Ca e $\mathrm{Mg}$ no solo, as que mais se destacaram foram as três cultivares de tremoço-branco e a aveia-preta.

Termos para indexação: adubos orgânicos, fitomassa, nutrição da planta, nitrogênio, relação plantasolo.

\section{Behaviour of temperate green manure species in a mountain region of the Rio de Janeiro State, Brazil}

\begin{abstract}
The objective of this work was to evaluate the behaviour of temperate green manure species in an Inceptisol with two different fertility levels, in an area of high elevation $(1,100 \mathrm{~m})$. Two field experiments were carried out in Nova Friburgo County, Rio de Janeiro State, Brazil, with the following species: Avena strigosa Schieb., Lollium multiflorum Lam., Lathyrus sativus L., Vicia sativa L., Vicia villosa Roth, used in the $2^{\text {nd }}$ experiment only, Ornithopus sativus Brot., Lupinus luteus L., Lupinus albus L. cv. Comum, cv. Multo Lupa Doce and cv. TRM 881, Trifolium repens L., Trifolium pratense L. cv. Achylesmarium and Trifolium vesiculosum Savi cv. Jacuí 52. The experimental design used was a randomized complete block design, with three replications. The species of best performance in relation to the above ground dry matter and total $\mathrm{N}$ on a soil with good fertility were L. albus (for all three cultivars used), L. luteus, $V$. sativa and A. strigosa. On a soil with low $\mathrm{P}, \mathrm{Ca}$ and $\mathrm{Mg}$, the best plant performances for above ground dry matter and total $\mathrm{N}$ were L. albus (all three cultivars) and A. strigosa.
\end{abstract}

Index terms: organic fertilizers, phytomass, plant nutrition, nitrogen, plant soil relations.

(1) Aceito para publicação em 16 de novembro de 2000

Extraído da Dissertação de Mestrado apresentada pelo primeiro autor à Universidade Federal Rural do Rio de Janeiro (UFRRJ).

(2)Empresa de Pesquisa Agropecuária do Estado do Rio de Janeiro (Pesagro), Estação Experimental de Nova Friburgo, Rua Euclides Solon Pontes, 30, CEP 28625-020 Nova Friburgo, RJ. E-mail: pesaeenf@netflash.com.br

(3)UFRRJ, Dep. de Solos, CEP 23851-970 Seropédica, RJ. E-mail: 1freire@marlin.com.br

(4) Embrapa-Centro Nacional de Pesquisa de Agrobiologia, km 47 da antiga via Rio-São Paulo, CEP 23851-970 Seropédica, RJ. E-mail:dejair@cnpab.embrapa.br, depolli@enpab.embrapa.br

\section{Introdução}

A adubação verde é uma prática importante na melhoria das condições químicas, físicas e biológicas do solo. Seus múltiplos efeitos têm sido constatados na proteção do solo, mediante a redução das perdas por erosão, o que proporciona ganho de matéria orgânica, aumento da capacidade de troca catiônica e da reciclagem dos nutrientes das camadas mais profundas para a superfície, e ameniza os problemas de compactação por meio da redução da densidade global, de controle de nematóides e de plantas concorrentes, pela cobertura do solo, e pela 
alelopatia (Mojtahedi et al., 1993; Amabile et al., 1994; Stampford et al., 1994; De-Polli et al., 1996; Nelson \& King, 1996; Biederbeck et al., 1998; Alcântara et al., 2000; Amabile et al., 2000; Favaretto et al., 2000; Jacobi \& Fleck, 2000).

Muitos autores têm noticiado o aporte de $\mathrm{N}$ ao solo, proveniente da fixação biológica por bactérias dos gêneros Rhizobium e Bradyrhizobium, quando se cultivam leguminosas como adubos verdes de culturas econômicas (De-Polli et al., 1996; Boddey et al., 1997). Já foi observado que o uso de adubos verdes na cultura do milho substituiu a aplicação de 80 a $100 \mathrm{~kg} \mathrm{ha}^{-1}$ de N sintético (De-Polli \& Chada, 1989; Araújo \& Almeida, 1993). Na região serrana fluminense, além do cultivo de adubos verdes tropicais no verão, as baixas temperaturas que ocorrem no inverno possibilitam o plantio das espécies de clima temperado. $\mathrm{O}$ cultivo destas no inverno pode ser de maior interesse para o agricultor.

O objetivo deste trabalho foi estudar o comportamento de algumas espécies vegetais utilizadas como adubo verde de inverno, nas condições da região serrana fluminense, e avaliar seu potencial de acumulação de fitomassa e nitrogênio.

\section{Material e Métodos}

No período de junho/1989 a outubro/1990 foram conduzidos, na Estação Experimental da Pesagro-Rio, em Nova Friburgo, RJ, a cerca de $1.100 \mathrm{~m}$ de altitude, dois experimentos de campo, para avaliar o comportamento de espécies de adubos verdes de inverno. As gramíneas usadas foram a aveia-preta (Avena strigosa Schieb.) e o azevém-anual (Lollium multiflorum Lam.), e as leguminosas compreenderam chícharo (Lathyrus sativus L.), ervilhaca-comum (Vicia sativa L.), ervilhacapeluda (Vicia villosa Roth), utilizada somente no segundo experimento, serradela-flor-rosa (Ornithopus sativus Brot.), tremoço-amarelo (Lupinus luteus L.), tremoço-branco (Lupinus albus L.), cultivares Comum, Multo Lupa Doce e TRM 881, trevo-branco (Trifolium repens L.), trevo-vermelho cultivar Achylesmarium (Trifolium pratense L.) e trevo-vesiculoso cultivar Jacuí 52 (Trifolium vesiculosum Savi)

O primeiro experimento foi instalado em junho de 1989 e o segundo, em maio de 1990, ambos num Cambissolo Háplico Tb distrófico (Embrapa, 1999), em dois locais próximos, mas que apresentavam diferenças em sua fertilidade. As análises químicas do solo foram feitas pelos métodos descritos em Embrapa (1979), em amostras compostas oriundas de 12 subamostras, coletadas a $0-0,30 \mathrm{~m}$ de profundidade, cujos resultados foram, no primeiro experimento: $\mathrm{pH}$ em $\mathrm{H}_{2} \mathrm{O}, 5,5 ; \mathrm{Al}^{+3}, 0,2 \mathrm{cmol}_{\mathrm{c}} \mathrm{kg}^{-1} ; \mathrm{Ca}^{+2}$, $1,4 \mathrm{cmol}_{\mathrm{c}} \mathrm{kg}^{-1}, \mathrm{Mg}^{+2}, 1,0 \mathrm{cmol}_{\mathrm{c}} \mathrm{kg}^{-1} ; \mathrm{P}, 33 \mathrm{mg} \mathrm{kg}^{-1} ; \mathrm{K}$, $124 \mathrm{mg} \mathrm{kg}^{-1}$; $\mathrm{C}$ orgânico, 13,9 $\mathrm{g} \mathrm{kg}^{-1} \mathrm{e} \mathrm{N}$ total, $1,6 \mathrm{~g} \mathrm{~kg}^{-1}$, e no segundo experimento: $\mathrm{pH}$ em $\mathrm{H}_{2} \mathrm{O}, 5,5 ; \mathrm{Al}^{+3}$, $0,2 \mathrm{cmol}_{\mathrm{c}} \mathrm{kg}^{-1} ; \mathrm{Ca}^{+2}, 0,3 \mathrm{cmol}_{\mathrm{C}} \mathrm{kg}^{-1} ; \mathrm{Mg}^{+2}, 0,3$ cmol $_{\mathrm{c}} \mathrm{kg}^{-1}$; $\mathrm{P}, 3 \mathrm{mg} \mathrm{kg}{ }^{-1}$; K, $74 \mathrm{mg} \mathrm{kg}^{-1}$; C orgânico, 7,5 $\mathrm{g} \mathrm{kg}^{-1} \mathrm{e} \mathrm{N}$ total, $0,8 \mathrm{~g} \mathrm{~kg}^{-1}$.

O delineamento experimental utilizado nos dois experimentos foi o de blocos ao acaso, em parcelas subdivididas, com adubos verdes na parcela principal, e as épocas de avaliação, nas subparcelas. No primeiro experimento, utilizaram-se 12 adubos verdes, duas épocas de avaliação e três repetições, totalizando 72 subparcelas $(12 \times 2 \times 3)$; no segundo experimento, utilizaram-se 13 adubos verdes, três épocas de avaliação e três repetições, totalizando 117 subparcelas $(13 \times 3 \times 3)$. As parcelas tinham as dimensões de 2,0 × 2,5 m cada. O espaçamento utilizado foi de $0,25 \mathrm{~m}$ entre linhas, com, aproximadamente, 10 plantas por metro linear. As leguminosas foram submetidas a inoculações segundo as recomendações de De-Polli \& Franco (1985), com as estirpes de rizóbio recomendadas pela Embrapa-Centro Nacional de Pesquisa de Agrobiologia, Seropédica, RJ. No primeiro experimento, foi realizada uma capina manual aos 58 dias após a semeadura (DAS), e no segundo, duas: aos 35 e 50 dias após a semeadura

Durante a condução do primeiro experimento, foram realizadas coletas de materiais da parte aérea e raízes aos 79 e 119 DAS dos adubos verdes, e no segundo experimento, as coletas foram feitas aos 51, 93 e 138 DAS. Na última coleta de cada experimento, a maioria das plantas, de cada espécie de adubo verde, estava em floração. Em cada época de avaliação/subparcelas, as plantas das duas linhas centrais, numa extensão de $0,80 \mathrm{~m}$, foram cortadas rente ao solo, e pesadas, para determinação da matéria fresca. As raízes dessas plantas, até a profundidade de $0,25 \mathrm{~m}$, foram retiradas com o solo aderido, sacudidas, lavadas, e após escorrido o excesso de água, foi obtido o peso de sua matéria fresca. Os nódulos das leguminosas foram coletados das raízes das cinco primeiras plantas colhidas. Amostras da parte aérea e raízes, colhidas de cada subparcela, foram, então, separadas, e, junto com os nódulos coletados, colocadas para secar em estufa com circulação de ar a $65^{\circ} \mathrm{C}$, até atingir peso constante, para obtenção do peso da matéria seca. Este material foi então moído, e usado para determinar o $\mathrm{N}$ total (Kjeldahl) da parte aérea e das raízes. 
A altura das plantas foi determinada pela medição das seis plantas dispostas no centro das duas linhas de coleta O índice de cobertura do solo (ICS), variável de 0 a 1 , foi obtido em dia ensolarado, ao meio dia, aproximadamente, estimando-se a área ocupada pela sombra das plantas sobre o solo da subparcela correspondente às duas linhas centrais, e calculando-se a seguinte relação: ICS = área da sombra na subparcela/área total da subparcela.

Os dados foram submetidos à análise de variância e as médias comparadas pelo teste de Tukey a $5 \%$ de probabilidade.

\section{Resultados e Discussão}

No solo do primeiro experimento, que apresentava boas condições de fertilidade, destacaram-se na produção de matéria fresca, na primeira coleta, aos 79 dias após a semeadura (DAS), as cultivares de tremoço-branco e o tremoço-amarelo (Tabela 1). Entretanto, a maior umidade deste último deixou-o no grupo de espécies com destaque intermediário, quanto à produção de matéria seca, junto com a ervilhaca-comum, o azevém-anual e a aveia-preta. Os demais adubos verdes tiveram menor acúmulo de matéria vegetal na parte aérea aos 79 DAS. $\mathrm{O}$ crescimento inicial dos adubos verdes na região serrana fluminense não diferiu muito do obtido na Estação Experimental da EMPASC, em Campos Novos, SC (Calegari et al., 1992). Entretanto, o chícharo, naquele local, foi mais agressivo que a ervilhaca, enquanto na região serrana fluminense aconteceu o oposto. Aos 119 DAS, as que mais se destacaram quanto à produção de matéria seca da parte aérea foram as três cultivares de tremoço-branco, o tremoço-amarelo, a ervilhaca-comum e a aveiapreta. A serradela-flor-rosa apresentou crescimento muito lento durante todo seu ciclo. Os níveis de produção de fitomassa alcançados pelas três cultivares de tremoço-branco e aveia-preta foram maiores que os relatados por Gouveia \& Almeida (1997) na região serrana fluminense, em Paty do Alferes, e as produções de fitomassa da aveia-preta e da ervilhacacomum foram maiores, e a do chícharo foi menor do que os encontrados por Aita et al. (1994) em Santa Maria, RS.

O azevém-anual e a aveia-preta foram as espécies que acumularam maior quantidade de massa fresca de raízes aos 79 DAS. No entanto, somente o primeiro despontou com relação à produção de massa seca nesta época, com $0,63 \mathrm{tha}^{-1}$, enquanto aveiapreta e trevo-vermelho produziram $0,35 \mathrm{e} 0,26 \mathrm{t} \mathrm{ha}^{-1}$, respectivamente. Aos 119 DAS o azevém-anual, a aveia-preta, o trevo-vermelho e o tremoço-branco cultivar Multo Lupa Doce foram os adubos verdes que proporcionaram a produção de maior quantidade de matéria seca de raízes. O azevém-anual acumulou mais matéria em suas raízes $\left(5,14 \mathrm{t} \mathrm{ha}^{-1}\right)$ que em sua parte aérea $\left(4,30 \mathrm{tha}^{-1}\right)$, o que revela sua elevada capacidade de explorar os primeiros $0,25 \mathrm{~m}$ de camada mais fértil do solo. Os demais adubos verdes se igualaram com relação à produção de matéria seca de raízes nesta época. A nodulação das cultivares de tremoço-branco e tremoço-amarelo foi bas-

Tabela 1. Valores médios de massa fresca e seca da parte aérea e raízes $\left(t \mathrm{tha}^{-1}\right)$ de 12 adubos verdes, obtidos em duas épocas após a semeadura (Experimento 1) $)^{(1)}$.

\begin{tabular}{|c|c|c|c|c|c|c|c|c|}
\hline \multirow[t]{3}{*}{ Adubos verdes } & \multicolumn{4}{|c|}{ Massa da parte aérea } & \multicolumn{4}{|c|}{ Massa de raízes } \\
\hline & \multicolumn{2}{|c|}{79 DAS } & \multicolumn{2}{|c|}{ 119 DAS } & \multicolumn{2}{|c|}{79 DAS } & \multicolumn{2}{|c|}{$119 \mathrm{DAS}$} \\
\hline & Fresca & Seca & Fresca & Seca & Fresca & Seca & Fresca & Seca \\
\hline Aveia-preta & $7,71 b c$ & $0,79 \mathrm{bcd}$ & $37,74 a b c$ & 5,31 abcd & $3,80 \mathbf{a}$ & $0,35 \mathrm{~b}$ & $12,44 \mathrm{bc}$ & $2,72 a b$ \\
\hline Azevém-anual & $6,15 \mathrm{cde}$ & $0,79 \mathrm{bce}$ & 30,51 abcd & 4,30 bcde & $4,48 a$ & $0,63 \mathbf{a}$ & $21,51 \mathrm{a}$ & $5,14 a$ \\
\hline Chícharo & $2,50 \mathrm{e}$ & $0,33 \mathrm{e}$ & $23,68 \mathrm{bcd}$ & $2.74 \mathrm{de}$ & $0,30 \mathrm{c}$ & $0,09 \mathrm{e}$ & $3,39 \mathrm{~d}$ & $0,55 \mathrm{~b}$ \\
\hline Ervilhaca-comum & $7,33 \mathrm{bcd}$ & $0,98 \mathrm{~b}$ & $45,97 \mathbf{a}$ & $6,31 \mathrm{abc}$ & $0,79 b c$ & $0,14 \mathrm{de}$ & $5,22 \mathrm{bcd}$ & $0,45 \mathrm{~b}$ \\
\hline Serradela-flor-rosa & $4,30 \mathrm{cde}$ & $0,49 \mathrm{cde}$ & $10,65 d$ & $1,43 \mathrm{e}$ & $0,96 \mathrm{bc}$ & $0,12 \mathrm{de}$ & $5,45 \mathrm{bcd}$ & $0,95 \mathrm{~b}$ \\
\hline Tremoço-amarelo & $8,83 \mathrm{abc}$ & $0,87 \mathrm{bc}$ & $38,07 \mathrm{abc}$ & $7,05 \mathrm{ab}$ & $0,75 b c$ & $0,09 \mathrm{e}$ & $3,16 \mathrm{~d}$ & $0,90 \mathrm{~b}$ \\
\hline Tremoço-branco cv. Comum & $8,70 \mathrm{abc}$ & $1,16 a b$ & $44,58 \mathrm{ab}$ & $7,73 \mathrm{a}$ & $0,69 \mathrm{bc}$ & $0,14 \mathrm{de}$ & $6,64 \mathrm{bcd}$ & $1,77 \mathrm{~b}$ \\
\hline Tremoço-branco cv. ML Doce & $11,80 \mathrm{ab}$ & $1,44 a$ & $37,76 \mathrm{abc}$ & $6,34 \mathrm{abc}$ & $0,74 \mathrm{bc}$ & $0,17 \mathrm{cde}$ & $6,18 \mathrm{bcd}$ & $2,10 \mathrm{ab}$ \\
\hline Tremoço-branco cv. TRM 881 & $12,52 \mathrm{a}$ & $1,44 a$ & $49,20 \mathbf{a}$ & $7,87 \mathbf{a}$ & $1,49 \mathrm{~b}$ & $0,21 \mathrm{~cd}$ & $3,99 \mathrm{~d}$ & $1,62 \mathrm{~b}$ \\
\hline Trevo-branco & $2,77 \mathrm{de}$ & $0,27 \mathrm{e}$ & $11,78 \mathrm{~d}$ & $1,53 \mathrm{e}$ & $0,56 \mathrm{bc}$ & $0,18 \mathrm{cde}$ & $3,57 \mathrm{~d}$ & $0,34 \mathrm{~b}$ \\
\hline Trevo-vermelho & $5,29 \mathrm{cde}$ & $0,51 \mathrm{cde}$ & $32,09 \mathrm{abcd}$ & $3,80 \mathrm{cde}$ & $1,41 \mathrm{~b}$ & $0,26 b c$ & $13,46 a b$ & $2,35 \mathrm{ab}$ \\
\hline Trevo-vesiculoso & $4,23 \mathrm{cde}$ & $0,36 \mathrm{de}$ & $16,43 \mathrm{~cd}$ & $3,36 \mathrm{cde}$ & $0,82 \mathrm{bc}$ & $0,19 \mathrm{cde}$ & $4,28 \mathrm{~cd}$ & $0,86 \mathrm{~b}$ \\
\hline
\end{tabular}

\footnotetext{
${ }^{(1)}$ Médias seguidas pela mesma letra, nas colunas, não diferem significativamente pelo teste de Tukey a 5\% de probabilidade; DAS: dias após a semeadura.
} 
tante superior à das demais espécies, nas duas épocas de coleta (Tabela 2). O tremoço-amarelo produziu $460 \mathrm{mg}$ de nódulos secos por planta aos 119 DAS. Esta leguminosa apresenta nodulação em forma de colar, cobrindo toda a parte superior de sua raiz principal, o que refletiu no elevado peso encontrado em seus nódulos. A nodulação das demais leguminosas foi bastante inferior à obtida pelos tremoços. Entretanto, esses resultados devem ser analisados com cuidado, pois essas espécies possuem nódulos pequenos e mais leves, em comparação com os dos tremoços; além disso, a nodulação do chícharo e ervilhaca-comum estão dentro da faixa normalmente obtida nos estados do Sul do País (Calegari et al., 1992).

Os adubos verdes que mais acumularam $\mathrm{N}$ na parte aérea aos 79 DAS foram as três cultivares de tremoçobranco. No entanto, aos 119 DAS, dado o rápido crescimento do tremoço-amarelo e da ervilhaca-comum após a primeira coleta, essas espécies se equipararam estatisticamente às três cultivares de tremoçobranco. Quantidades de N na parte aérea das plantas acima de $220 \mathrm{~kg} \mathrm{ha}^{-1}$ foram obtidas por tremoço-branco cultivar Comum, tremoço-amarelo e ervilhaca-comum, aos 119 DAS. Os trevos vermelho e vesiculoso acumularam na parte aérea quantidades intermediárias de $\mathrm{N}$, em torno de $112 \mathrm{~kg} \mathrm{ha}^{-1}$. A aveia-preta acumulou pouco mais de $100 \mathrm{~kg} \mathrm{ha}^{-1}$ de $\mathrm{N}$ na parte aérea, mostrando a boa capacidade dessa gramínea de produzir fitomassa e absorver $\mathrm{N}$ do solo. O azevém-anual e o trevo-vermelho foram as espécies que mais acumularam $\mathrm{N}$ nas raízes aos
79 DAS, cerca de 7,5 e 5,3 $\mathrm{kg} \mathrm{ha}^{-1}$, respectivamente. Na segunda coleta, essas espécies chegaram a acumular 37,1 e $38,8 \mathrm{~kg} \mathrm{ha}^{-1}$ de $\mathrm{N}$ em suas raízes, respectivamente. As três cultivares de tremoço-branco, o tremoço-amarelo, a aveia-preta, a serradela-florrosa e o trevo-vesiculoso também se destacaram com relação ao $\mathrm{N}$ acumulado nas raízes. Os adubos verdes que mais acumularam $\mathrm{N}$ total na planta (parte aérea + raízes) aos 79 DAS foram as cultivares de tremoço-branco. Essas espécies apresentaram um crescimento inicial bastante acelerado, destacandose das demais. Aos 119 DAS, além dessas, destacaram-se o tremoço-amarelo e a ervilhaca-comum. A aveia-preta, o trevo-vesiculoso e o trevo-vermelho obtiveram acúmulo de $\mathrm{N}$ total semelhante ao das três cultivares de tremoço-branco. Os valores mais elevados de acúmulo de $\mathrm{N}$ total na planta foram obtidos pela cultivar Comum de tremoço-branco e tremoço-amarelo, com 251,6 e $247,7 \mathrm{~kg} \mathrm{ha}^{-1}$ de $\mathrm{N}$, respectivamente. A ervilhaca-comum acumulou $228,1 \mathrm{~kg} \mathrm{ha}^{-1}$ de nitrogênio.

Os bons resultados de produção do azevém-anual, aveia-preta e ervilhaca-comum também indicam a possibilidade do uso dessas espécies na região serrana fluminense para produção de forragem. Nos estados do Sul do País essas espécies são recomendadas para este fim, obtendo grande aceitação pelos agricultores (Calegari et al., 1992), e podendo, inclusive, ser combinadas, em cultivo consorciado, aveia-preta com ervilhaca-peluda (Jannink et al., 1996), e aveia-preta com ervilhaca-comum (Heinrichs \& Fancelli, 1999; Amado et al., 2000).

Tabela 2. Peso médio de nódulos secos $\left(\mathrm{mg} \mathrm{planta}^{-1}\right)$ de dez leguminosas e teor de nitrogênio total $\left(\mathrm{kg} \mathrm{ha}^{-1}\right)$ acumulado na parte aérea e raízes de 12 adubos verdes, obtidos em duas épocas após a semeadura (Experimento 1)(1).

\begin{tabular}{|c|c|c|c|c|c|c|}
\hline \multirow[t]{2}{*}{ Adubos verdes } & \multicolumn{2}{|c|}{ Peso de nódulos secos } & \multicolumn{2}{|c|}{ N total na parte aérea } & \multicolumn{2}{|c|}{$\mathrm{N}$ total nas raízes } \\
\hline & 79 DAS & $119 \mathrm{DAS}$ & 79 DAS & 119 DAS & 79 DAS & $119 \mathrm{DAS}$ \\
\hline Aveia-preta & $-^{(2)}$ & - & $20,4 \mathrm{~cd}$ & $100,3 \mathrm{cde}$ & 4,1 bcd & $21,5 \mathrm{abc}$ \\
\hline Azevém-anual & - & - & $12,8 \mathrm{~d}$ & $52,5 \mathrm{de}$ & $7,5 \mathrm{a}$ & $37,1 \mathrm{ab}$ \\
\hline Chícharo & $15 \mathrm{c}$ & $25 \mathrm{c}$ & $11,3 \mathrm{~d}$ & 74,3 cde & $1,5 \mathrm{de}$ & $9,7 \mathrm{bc}$ \\
\hline Ervilhaca-comum & $8 \mathrm{c}$ & $12 \mathrm{c}$ & $33,9 b c$ & $222,6 \mathrm{ab}$ & $2,6 \mathrm{cde}$ & $5,5 \mathrm{c}$ \\
\hline Serradela-flor-rosa & $1 \mathrm{c}$ & $5 c$ & $11,0 \mathrm{~d}$ & $25,6 \mathrm{e}$ & $1,7 \mathrm{de}$ & $12,4 a b c$ \\
\hline Tremoço-amarelo & $158 \mathrm{ab}$ & $460 \mathbf{a}$ & $35,6 \mathrm{bc}$ & $231,3 \mathrm{ab}$ & $2,5 \mathrm{cde}$ & $16,4 a b c$ \\
\hline Tremoço-branco cv. Comum & $125 \mathrm{ab}$ & $189 \mathrm{~b}$ & $42,4 \mathrm{ab}$ & $236,6 \mathbf{a}$ & 2,4 cde & $15,0 \mathrm{abc}$ \\
\hline Tremoço-branco cv. ML Doce & $119 b$ & $161 \mathrm{bc}$ & $56,5 \mathrm{a}$ & $166,8 \mathrm{abcd}$ & $2,9 \mathrm{cde}$ & $26,6 \mathrm{abc}$ \\
\hline Tremoço-branco cV. TRM 881 & $210 \mathrm{a}$ & $285 b$ & $51,8 \mathrm{a}$ & $187,6 \mathrm{abc}$ & 3,5 bcde & $18,2 \mathrm{abc}$ \\
\hline Trevo-branco & $1 \mathrm{c}$ & $3 \mathrm{c}$ & $9,0 \mathrm{~d}$ & $55,2 \mathrm{de}$ & $4,2 \mathrm{bcd}$ & $7,2 \mathrm{c}$ \\
\hline Trevo-vermelho & $1 \mathrm{c}$ & $6 c$ & $17,2 \mathrm{~d}$ & $112,3 \mathrm{bcde}$ & $5,3 a b$ & $38,8 \mathrm{a}$ \\
\hline Trevo-vesiculoso & $1 \mathrm{c}$ & $6 c$ & $9,9 \mathrm{~d}$ & 112,5 bcde & $4,4 \mathrm{bc}$ & $15,6 \mathrm{abc}$ \\
\hline
\end{tabular}

${ }^{(1)}$ Médias seguidas pela mesma letra, nas colunas, não diferem significativamente pelo teste de Tukey a $5 \%$ de probabilidade; DAS: dias após a semeadura (2) Não se aplica 
No segundo experimento, os adubos verdes foram cultivados em solo com nível baixo de $\mathrm{P}$, de $\mathrm{Ca}$ e de $\mathrm{Mg}$, em sua camada arável. Aos 51 DAS, as espécies de adubos verdes que mais se destacaram com relação à produção de matéria seca foram as três cultivares de tremoço-branco e a aveia-preta (Tabela 3). Resultados semelhantes foram obtidos por essas espécies aos $93 \mathrm{DAS}$. Com relação à produção de matéria fresca da parte aérea, aos 138 DAS, houve destaque apenas para as três cultivares de tremoço-bran$\mathrm{co}$, com produções acima de $56 \mathrm{tha}^{-1}$. Quanto à produção de matéria seca, destacou-se, além dessas, a aveia-preta, com 7,44 tha-1. O excelente desempenho da aveia-preta sob condições de baixo $\mathrm{P}, \mathrm{Ca} \mathrm{e}$ Mg mostra a característica importante dessa planta, de ser pouco exigente em relação a solos (Calegari et al., 1992). Entre oito espécies de plantas, os tremoços foram as mais eficientes em absorver $P$ nas várias concentrações testadas (Loneragan \& Asher, 1969). Os possíveis benefícios oriundos da atividade de fungos micorrízicos também devem ser considerados (Espindola et al., 1998). O tremoço-amarelo, a ervilhaca-comum e o trevo-vermelho não conseguiram repetir o desempenho que tiveram no primeiro experimento, indicando, portanto, que são mais exigentes em fertilidade do solo.

Com relação à produção de raízes aos $51 \mathrm{DAS}$, houve diferenças significativas entre as espécies, refletindo, possivelmente, a velocidade inicial de crescimento, bastante diferenciada entre os diversos adubos verdes testados. Assim, as espécies que acumularam menos matéria fresca nas raízes - os trevos e a serradela-flor-rosa - foram as que tiveram maior dificuldade de estabelecimento. Aos 93 DAS, aumentaram as diferenças na matéria seca acumulada nas raízes dessas espécies com relação à das demais, o que mostra as dificuldades delas de se estabelecerem em condições de baixa fertilidade. Os adubos verdes que acumularam maior quantidade de matéria fresca nas raízes aos 138 DAS foram as três cultivares de tremoço-branco, a aveia-preta e o azevémanual. Este último confirmou os resultados obtidos no primeiro experimento como a espécie que mais acumula rizomassa, obtendo 14,42 e $3,25 \mathrm{t} \mathrm{ha}^{-1} \mathrm{de}$ matéria fresca e seca, respectivamente.

O índice de cobertura do solo foi maior com cultivares de tremoço-branco e aveia-preta aos 51 DAS

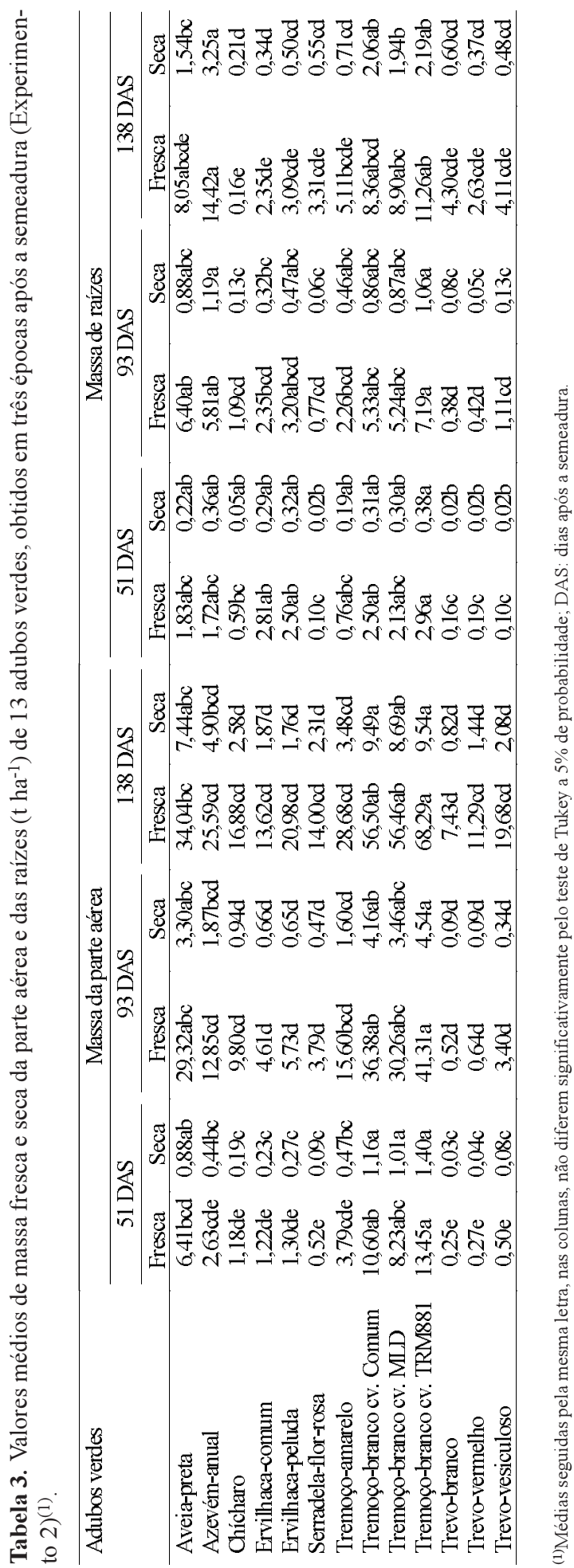

Pesq. agropec. bras., Brasília, v. 36, n. 12, p. 1461-1468, dez. 2001 
(Tabela 4). Essas espécies, aos 93 DAS, praticamente já cobriam todo o solo das parcelas, não permitindo o crescimento de plantas concorrentes. Aos 138 DAS, não houve diferença significativa entre as espécies de adubos verdes em relação a este parâmetro, por causa do crescimento das demais espécies.

Aos 51 DAS, as três cultivares de tremoço-branco foram as que obtiveram o maior número de nódulos por planta (Tabela 5). Aos 93 DAS, destacaramse as cultivares de tremoço-branco TRM 881 e Comum, com 72 e 91 nódulos por planta, vindo a seguir a cultivar Multo Lupa Doce, com 68 nódulos por planta. Dado o processo de senescência nodular que se intensifica com as proximidades do final do ciclo (Barradas et al., 1989), o número de nódulos caiu para cerca da metade aos $138 \mathrm{DAS}$, enquanto o número de nódulos nas demais leguminosas (com exceção da ervilhaca-peluda) aumentou consideravelmente. Esses resultados estão, provavelmente, ligados ao ciclo mais longo dessas culturas em relação aos tremoços.

Aos 51 DAS, o $\mathrm{N}$ acumulado na parte aérea dos adubos verdes foi maior nas cultivares de tremoçobranco e aveia-preta. Aos 93 DAS, apenas as primeiras se mantiveram como destaque em relação a esse

Tabela 4. Valores médios do índice de cobertura do solo (escala 0-1) e altura da parte aérea $(\mathrm{cm})$ de 13 adubos verdes de inverno, obtidos em três épocas após a semeadura (Experimento 2$)^{(1)}$.

\begin{tabular}{|c|c|c|c|c|c|c|}
\hline \multirow[t]{2}{*}{ Adubos verdes } & \multicolumn{3}{|c|}{ Índice de cobertura do solo } & \multicolumn{3}{|c|}{ Altura da parte aérea } \\
\hline & $51 \mathrm{DAS}$ & $93 \mathrm{DAS}$ & $138 \mathrm{DAS}$ & $51 \mathrm{DAS}$ & $93 \mathrm{DAS}$ & 138 DAS \\
\hline Aveia-preta & $0,38 \mathrm{ab}$ & $0,85 \mathrm{a}$ & $1,00 \mathrm{a}$ & $16 b c$ & $54 \mathrm{~b}$ & $127 \mathrm{a}$ \\
\hline Azevém-anual & $0,18 \mathrm{c}$ & $0,39 b c$ & $0,93 a$ & $9 \mathrm{~cd}$ & $19 \mathrm{~cd}$ & $72 b$ \\
\hline Chícharo & $0,12 \mathrm{c}$ & $0,33 b c$ & $0,72 \mathbf{a}$ & $10 \mathrm{~cd}$ & $22 \mathrm{~cd}$ & $39 \mathrm{~cd}$ \\
\hline Ervilhaca-comum & $0,13 \mathrm{c}$ & $0,27 \mathrm{c}$ & $0,68 \mathbf{a}$ & $10 \mathrm{~cd}$ & $23 \mathrm{~cd}$ & $43 \mathrm{~cd}$ \\
\hline Ervilhaca-peluda & $0,13 \mathrm{c}$ & $0,27 \mathrm{c}$ & $0,62 a$ & $7 \mathrm{~cd}$ & $17 \mathrm{~cd}$ & $39 \mathrm{~d}$ \\
\hline Serradela-flor-rosa & $0,09 \mathrm{c}$ & $0,27 \mathrm{c}$ & $0,65 a$ & $6 \mathrm{~cd}$ & $14 \mathrm{~cd}$ & $41 \mathrm{~cd}$ \\
\hline Tremoço-amarelo & $0,22 \mathrm{bc}$ & $0,56 \mathrm{~b}$ & $0,97 \mathrm{a}$ & $13 \mathrm{~cd}$ & $29 \mathrm{c}$ & $62 \mathrm{bc}$ \\
\hline Tremoço-branco cv. Comum & $0,43 \mathrm{a}$ & $1,00 \mathbf{a}$ & $1,00 \mathbf{a}$ & $28 \mathrm{a}$ & $75 a$ & $129 a$ \\
\hline Tremoço-branco cv. ML Doce & $0,39 \mathbf{a}$ & $0,97 \mathbf{a}$ & $1,00 \mathrm{a}$ & $25 \mathrm{ab}$ & $64 a b$ & $122 \mathrm{a}$ \\
\hline Tremoço-branco cv. TRM 881 & $0,46 \mathbf{a}$ & $1,0 \mathrm{a}$ & $1,00 \mathbf{a}$ & $27 \mathrm{a}$ & $68 \mathrm{ab}$ & $132 a$ \\
\hline Trevo-branco & $0,08 \mathrm{c}$ & $0,22 \mathrm{c}$ & $0,52 \mathrm{a}$ & $6 \mathrm{~cd}$ & $10 \mathrm{~d}$ & $23 \mathrm{~d}$ \\
\hline Trevo-vermelho & $0,09 \mathrm{c}$ & $0,18 \mathrm{c}$ & $0,57 \mathbf{a}$ & $7 \mathrm{~cd}$ & $13 \mathrm{~cd}$ & $22 d$ \\
\hline Trevo-vesiculoso & $0,07 \mathrm{c}$ & $0,22 \mathrm{c}$ & $0,58 \mathbf{a}$ & $5 d$ & $10 \mathrm{~d}$ & $38 \mathrm{~cd}$ \\
\hline
\end{tabular}

(1)Médias seguidas pela mesma letra, nas colunas, não diferem significativamente pelo teste de Tukey a $5 \%$ de probabilidade; DAS: dias após a semeadura.

Tabela 5. Valores médios de nitrogênio total acumulado na parte aérea e nas raízes $\left(\mathrm{kg} \mathrm{ha}^{-1}\right)$ e número de nódulos por planta de 13 adubos verdes de inverno, obtidos em três épocas após a semeadura (Experimento 2) $)^{(1)}$.

\begin{tabular}{|c|c|c|c|c|c|c|c|c|c|}
\hline \multirow[t]{2}{*}{ Adubos verdes } & \multicolumn{3}{|c|}{$\mathrm{N}$ total da parte aérea } & \multicolumn{3}{|c|}{$\mathrm{N}$ total das raízes } & \multicolumn{3}{|c|}{ Nódulos } \\
\hline & $51 \mathrm{DAS}$ & 93 DAS & $138 \mathrm{DAS}$ & $51 \mathrm{DAS}$ & $93 \mathrm{DAs}$ & $38 \mathrm{DAS}$ & $51 \mathrm{DAS}$ & $93 \mathrm{DAS}$ & $138 \mathrm{DAS}$ \\
\hline Aveia-preta & $32,8 \mathrm{a}$ & $53,3 \mathrm{c}$ & 88,0 abcd & $2,7 \mathrm{bcd}$ & $7,8 \mathrm{ab}$ & $10,1 \mathrm{ab}$ & $-(2)$ & - & - \\
\hline Azevém-anual & $13,0 \mathrm{bc}$ & $34,1 \mathrm{c}$ & $52,4 d$ & 3,9abcd & $9,3 a b$ & $17,8 \mathrm{ab}$ & - & - & - \\
\hline Chícharo & $6,3 \mathrm{c}$ & $32,0 \mathrm{c}$ & $75,0 \mathrm{bcd}$ & $0,93 \mathrm{~cd}$ & $2,9 \mathrm{~b}$ & $4,0 \mathrm{~b}$ & $5 b$ & $4 c$ & $8 \mathrm{~cd}$ \\
\hline Ervilhaca-comum & $7,4 \mathrm{c}$ & $16,5 \mathrm{c}$ & $50,6 \mathrm{~d}$ & $5,2 \mathrm{abc}$ & $5,7 \mathrm{~b}$ & $4,9 \mathrm{~b}$ & $10 \mathrm{~b}$ & $13 \mathrm{c}$ & 10bcd \\
\hline Ervilhaca-peluda & $8,5 \mathrm{c}$ & $16,4 \mathrm{c}$ & $36,9 \mathrm{~d}$ & $5,5 \mathrm{ab}$ & $6,5 \mathrm{ab}$ & $9,8 \mathrm{ab}$ & $3 b$ & $4 c$ & $17 \mathrm{bcd}$ \\
\hline Serradela-flor-rosa & $2,8 \mathrm{c}$ & $11,1 \mathrm{c}$ & $31,2 d$ & $0,3 \mathrm{~d}$ & $1,4 \mathrm{~b}$ & $5,2 \mathrm{~b}$ & $14 \mathrm{~b}$ & $19 \mathrm{c}$ & $40 a$ \\
\hline Tremoço-amarelo & $14,2 \mathrm{bc}$ & $31,4 \mathrm{c}$ & $76,4 \mathrm{~cd}$ & $1,6 \mathrm{bcd}$ & $6,1 \mathrm{ab}$ & $8,6 a b$ & $5 b$ & $8 \mathrm{c}$ & $9 \mathrm{~cd}$ \\
\hline Tremoço-branco cv. Comum & $36,1 \mathrm{a}$ & $117,4 a$ & $161,4 \mathrm{ab}$ & $4,6 a b c d$ & $14,9 \mathbf{a}$ & $25,8 \mathrm{a}$ & $43 a$ & $91 a$ & $34 a b$ \\
\hline Tremoço-branco cv. ML Doce & $30,0 \mathrm{ab}$ & $102,8 \mathrm{ab}$ & $147,3 \mathrm{abc}$ & $5,1 \mathrm{abc}$ & $8,7 \mathrm{ab}$ & $12,5 \mathrm{ab}$ & $41 a$ & $68 \mathrm{~b}$ & $35 \mathrm{ab}$ \\
\hline Tremoço-branco cv. TRM 881 & $40,0 \mathrm{a}$ & $119,7 \mathbf{a}$ & $168,5 \mathrm{a}$ & $7,7 \mathrm{a}$ & $9,1 \mathrm{ab}$ & $18,5 \mathrm{a}$ & $37 \mathbf{a}$ & $72 \mathrm{ab}$ & $40 \mathrm{a}$ \\
\hline Trevo-branco & $1,2 \mathrm{c}$ & $2,3 \mathrm{c}$ & $18,5 \mathrm{~d}$ & $0,6 \mathrm{~d}$ & $1,5 b$ & $9,9 \mathrm{ab}$ & $4 b$ & $9 \mathrm{c}$ & $22 \mathrm{abc}$ \\
\hline Trevo-vermelho & $1,7 \mathrm{c}$ & $2,9 \mathrm{c}$ & $39,6 d$ & $0,5 \mathrm{~d}$ & $1,4 \mathrm{~b}$ & $7,3 \mathrm{ab}$ & $5 b$ & $10 \mathrm{c}$ & $13 \mathrm{bcd}$ \\
\hline Trevo-vesiculoso & $2,8 \mathrm{c}$ & $12,3 \mathrm{c}$ & $58,3 \mathrm{~cd}$ & $0,4 d$ & $2,4 \mathrm{~b}$ & $8,5 \mathrm{ab}$ & $5 b$ & $7 \mathrm{c}$ & $22 \mathrm{abc}$ \\
\hline
\end{tabular}

${ }^{(1)}$ Médias seguidas pela mesma letra, nas colunas, não diferem significativamente pelo teste de Tukey a 5\% de probabilidade; DAS: dias após a semeadura ${ }^{(2)}$ Não se aplica. 
parâmetro. Entretanto, na terceira coleta, aos 138 DAS, a aveia-preta voltou a figurar no grupo de espécies que mais acumularam $\mathrm{N}$ na parte aérea, expressando, assim, sua elevada capacidade em absorver o $\mathrm{N}$ do solo, mesmo nas condições de baixos níveis de $\mathrm{P}$, de $\mathrm{Ca}$ e de $\mathrm{Mg}$. As três cultivares de tremoço-branco acumularam, na parte aérea, aos 138 DAS, em solo com baixo nível de $\mathrm{P}, \mathrm{Ca}$ e $\mathrm{Mg}$, a média de $159,1 \mathrm{~kg} \mathrm{ha}^{-1}$ de nitrogênio. A média acumulada por essas plantas no primeiro experimento foi de $197,0 \mathrm{~kg} \mathrm{ha}^{-1}$ de N, o que mostra que, nas condições do segundo experimento, essas plantas deixaram de acumular mais de $30 \mathrm{~kg} \mathrm{ha}^{-1}$ de N, em média. No entanto, as leguminosas que foram mais influenciadas pelas condições do solo, ou seja: o tremoçoamarelo, a ervilhaca-comum e o trevo-vermelho, deixaram de acumular, na última coleta, na parte aérea, $154,9,172,0$ e $72,7 \mathrm{~kg} \mathrm{ha}^{-1} \mathrm{de} \mathrm{N}$, respectivamente. As espécies que acumularam maior quantidade de $\mathrm{N}$ nas raízes aos $51 \mathrm{DAS}$, foram as três cultivares de tremoço-branco, a ervilhaca-comum, a ervilhaca-peluda e o azevém-anual. Destas, apenas a ervilhacacomum não produziu bem na segunda coleta, destacando-se, também, nesta época, a aveia-preta e o tremoço-amarelo. Aos 138 DAS, além das cultivares da segunda coleta, destacaram-se, também, os trevos, que acumularam 7,3 a 9,9 $\mathrm{kg} \mathrm{ha}^{-1}$ de nitrogênio.

\section{Conclusões}

1. Independentemente das condições de fertilidade do solo, as espécies tremoço-branco (especialmente a cultivar TRM 881) e a aveia-preta destacam-se quanto à produção de fitomassa seca e à acumulação de $\mathrm{N}$ na parte aérea.

2. Quando a fertilidade do solo é boa, tremoçoamarelo e ervilhaca-comum também se destacam em produção de fitomassa seca e em acúmulo de $\mathrm{N}$ na parte aérea.

3. O azevém-anual apresenta grande produção de raízes secas, atingindo valores até maiores que os da produção da parte aérea.

\section{Agradecimentos}

Ao CNPq, pela concessão de bolsa de estudo ao primeiro autor; ao técnico agrícola Nelcyr Guimarães Castro, pelo apoio prestado.

\section{Referências}

AITA, C.; CERETTA, C. A.; THOMAS, L. A.; PAVINATO, A.; BAYER, C. Espécies de inverno como fonte de nitrogênio para o milho no sistema de cultivo mínimo e feijão em plantio direto. Revista Brasileira de Ciência do Solo, Campinas, v. 18, n. 1, p. 101-108, 1994.

ALCÂNTARA, F. A. de; FURTININETO,A. E.; PAULA, M. B. de; MESQUITA, A. de; MUNIZ, J. A. Adubação verde na recuperação da fertilidade de um Latossolo Vermelho-Escuro degradado. Pesquisa Agropecuária Brasileira, Brasília, v. 35, n. 2, p. 277-288, fev. 2000

AMABILE, R. F.; CORREIA, J. R.; FREITAS, P. L. de; BLANCANEAUX, P.; RAMOS, J. G. A. Efeito do manejo de adubos verdes na produção de mandioca (Manihot esculenta Crantz). Pesquisa Agropecuária Brasileira, Brasília, v. 29, n. 8, p. 1193-1199, ago. 1994.

AMABILE, R. F.; FANCELLI,A. L.; CARVALHO,A. M. de. Comportamento de espécies de adubos verdes em diferentes épocas de semeadura e espaçamentos na região dos cerrados. Pesquisa Agropecuária Brasileira, Brasília, v. 35, n. 1, p. $47-54$, jan. 2000

AMADO, T. J. C.; MIELNICZUK, J.; FERNANDES, S. B. V. Leguminosas e adubação mineral como fontes de nitrogênio para o milho em sistemas de preparo do solo. Revista Brasileira de Ciência do Solo, Campinas, v. 24, n. 1, p. 179-189, 2000.

ARAÚJO, A. P.; ALMEIDA, D. L. de. Adubação verde associada a fosfato de rocha na cultura do milho. Pesquisa Agropecuária Brasileira, Brasília, v. 28, n. 2, p. $245-$ 251, fev. 1993

BARRADAS, C. A. A.; BODDEY, L. H.; HUNGRIA, M. Seleção de cultivares de feijão e estirpes de Rhizobium para nodulação precoce e senescência tardia dos nódulos. Revista Brasileira de Ciência do Solo, Campinas, v. 13, n. 2, p. 169-179, 1989.

BIEDERBECK, V. O.; CAMPBELL, C. A.; RASIAH, V.; ZENTNER, R. P.; WEN, G. Soil quality attributes as influenced by annual legumes used as green manure. Soil Biology and Biochemistry, Oxford, v. 30, n. 8/9, p. 1177 1185, 1998.

BODDEY, R. M.; SA, J. C. de M.; ALVES, B. J. R.; URQUIAGA, S. The contribution of biological nitrogen fixation for sustainable agricultural systems in the tropics. Soil Biology \& Biochemistry, Oxford, v. 29, n. 5/6, p. $787-799,1997$.

Pesq. agropec. bras., Brasília, v. 36, n. 12, p. 1461-1468, dez. 2001 
CALEGARI, A.; MONDARDO, A.; BULISANI, E. A.; WILDER, L. do P.; COSTA, M. B. B. da;ALCÂNTARA, P. B.; MIYASAKA, S ; AMADO, T. J. C. Adubação verde no sul do Brasil. Rio de Janeiro: Assessoria e Serviços a Projetos em Agricultura Alternativa, 1992. 346 p

DE-POLLI, H.; CHADA, S. de S. Adubação verde incorporada ou em cobertura na produção do milho em solo de baixo potencial de produtividade. Revista Brasileira de Ciência do Solo, Campinas, v. 13, n. 3, p. 287-293, 1989.

DE-POLLI, H.; FRANCO, A. A. Inoculação de sementes de leguminosas. Seropédica: Embrapa-UAPNPBS, 1985. 31 p. (Circular Técnica, 1)

DE-POLLI, H.; GUERRA, J. G. M.; ALMEIDA, D. L. de; FRANCO, A. A. Adubação verde: parâmetros para avaliação de sua eficiência. In: CASTRO FILHO, C. de; MUZILLI, O. (Ed.). Manejo integrado de solos em microbacias hidrográficas. Londrina: Iapar, 1996. p. 225 242.

EMBRAPA. Centro Nacional de Pesquisa de Solos (Rio de Janeiro, RJ). Sistema brasileiro de classificação de solos. Brasília: Embrapa-SPI/Embrapa-CNPS, 1999. 412 p.

EMBRAPA. Serviço Nacional de Levantamento e Conservação de Solos (Rio de Janeiro, RJ). Manual de métodos de análises de solos. Rio de Janeiro, 1979. 1 v

ESPINDOLA, J. A. A.; ALMEIDA, D. L. de; GUERRA, J. G. M.; SILVA, E. M. R. da; SOUZA, F. A. de. Influência da adubação verde na colonização micorrízica e na produção da batata-doce. Pesquisa Agropecuária Brasileira, Brasília, v. 33, n. 3, p. 339-347, mar. 1998

FAVARETTO, N.; MORAES, A. de; MOTTA, A. C. V.; PREVEDELLO, B. M. S. Efeito da revegetação e da adubação de área degradada na fertilidade do solo e nas características da palhada. Pesquisa Agropecuária Brasileira, Brasília, v. 35, n. 2, p. 289-297, fev. 2000.
GOUVEIA, R. F. de; ALMEIDA, D. L. de. Avaliação de algumas características agronômicas de sete adubos verdes de inverno no Município de Paty do Alferes, RJ. Revista da Universidade Rural, Série Ciência da Vida Itaguaí, v. 19, p. 1-11, 1997.

HEINRICHS, R.; FANCELLI, A. L. Influência do cultivo consorciado de aveia preta (Avena strigosa Schieb.) e ervilhaca (Vicia sativa L.) na produção de fitomassa e no aporte de nitrogênio. Scientia Agricola, Piracicaba, v. 56, n. 1, p. 27-31, 1999

JACOBI, U. S.; FLECK, N. G. Avaliação do potencial alelopático de genótipos de aveia no início do ciclo. Pesquisa Agropecuária Brasileira, Brasília, v. 35, n. 1, p. 1119 , jan. 2000.

JANNINK, J. L.; LIEBMAN, M.; MERRICK, L. C. Biomass production and nitrogen accumulation in pea, oat, and vetch green manure mixtures. Agronomy Journal, Madison, v. 88, n. 2, p. 231-240, 1996

LONERAGAN, J. F.; ASHER, C. J. Response of plants to phosphate concentration in solution culture: II. Rate of phosphate absorption and its relation to growth. Soil Science, Madison, v. 103, n. 5, p. 311-318, 1969.

MOJTAHEDI, H.; SANTO, G. S.; INGHAM, R. E. Suppression of Meloidogyne chitwoodi with sudangrass cultivars as green manure. Journal of Nematology, Lakeland, v. 25, n. 2, p. 303-311, 1993.

NELSON, J. B.; KING, L. D. Green manure as a nitrogen source for wheat in the Southeastern United States. American Journal of Alternative Agriculture, Greenbelt, v. 11, n. 4, p. 182-189, 1996.

STAMPFORD, N. P.; ALBUQUERQUE, M. H.; SANTOS, D. R. Aproveitamento do nitrogênio pelo sorgo em sucessão a leguminosas incorporadas em diferentes épocas de corte. Revista Brasileira de Ciência do Solo, Campinas, v. 18, n. 2, p. 221-227, 1994. 